\title{
PAISAGEM: OBJETO DE TRABALHO DO ARQUITETO PAISAGISTA
}

\section{WANTUELFER GONÇALVES}

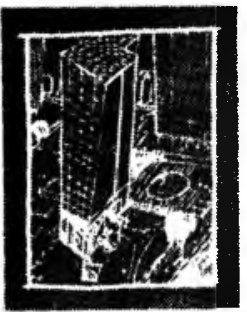

O projeto paisagístico, além de um desenho em papel vegetal, de algumas árvores e bancos de jardim, ou de uma figura bonita para um cartão postal é, para o profissional, uma necessidade de conhecimentos sociais, biológicos e estruturais. Mais ainda, precisa a compreensão do objeto de estudo como um todo e da sua subdivisão para a escala de trabalho. Visto como um espaço a ser trabalhado e preenchida a necessidade de dividí-lo é patente (Santos, 1985). A paisagem, no entanto, não é apenas um elemento espacial, mas um sistema espacial ou um geossistema, como querem alguns, ou um ecossistema, como querem outros, com todas as interações possíveis, incluindo a antropização.

Dividir esse ecossistema é, então, uma tarefa mais difícil ainda, mas que precisa ser feita para determinação e caracterização de um objeto em uma escala que possa ser trabalhável. Essa divisão é possível porque cada parte é uma unidade dinâmica do todo (Sotchava, 1977).

$\mathrm{O}$ arquiteto paisagista tem encontrado dificuldade em caracterizar o objeto de trabalho na escala menor, mas essa dificuldade pode estar embutida na definição do objeto como um todo e na definição do objeto como parte divisível desse todo.

\section{OS CONCEITOS}

O conceito mais antigo e ainda hoje tido entre os leigos relaciona paisagem com pintura ou com cenas bucólicas (Barsa, 1980), sem reconhecer o dinamismo natural entre os elementos que a compõem (Klink, 1974).

Além de cenário, o conceito de paisagem tem de estar impregnado de biologia, de participação humana, de evolução. Esses elementos conferem à porção do espaço denominada paisagem uma instabilidade, apesar de ser 0 conjunto indissociável (Bertrand, 1972).

A evolução da paisagem tanto pode acontecer de forma natural, demorada, como de forma acelerada pela atuação do homem. O homem acelera o processo evolutivo através de modificações e adaptações do ambiente as suas 
conveniências. A esse ambiente modificado, e não mais apenas ao cenário, é dado o nome de paisagem (Magnoli, 1987).

A antropização do espaço tem procurado a sociabilização do ambiente fazendo com que a paisagem ganhe, além do valor estético, o valor de uso através da participação constante do homem no ambiente. Essa antropização acontece também na forma contemplativa, sendo a paisagem uma função de quem a observa (Meinig, 1976; Pellegrino, 1990).

Assim, levando em conta a evolução constante, o suporte, a antropização e não deixando de lado o valor contemplativo, pode-se resumir o conceito de paisagem como sendo um elemento representado pela fisiografia, fisiologia e fisionomia do lugar, sendo instável porquanto é histórico e pessoal porque depende de quem a observa num momento definido (Gonçalves, 1990).

\section{AS PONTUALIDADES}

A necessidade de individualização do objeto paisagem para fins de projeto aponta para o reconhecimento da paisagem como um elemento pontual, vivenciando-se uma pontualidade geográfica histórica e antrópica.

A definição de paisagem como sendo o espaço de terreno que se abrange num lance de vista (Hollanda, 1986) é insuficiente para individualizar o objeto de estudo, pois um lance de vista pode abranger um espaço geográfico diferente em função da posição, da estatura, e do próprio órgão ocular de cada observador (Figura 1).
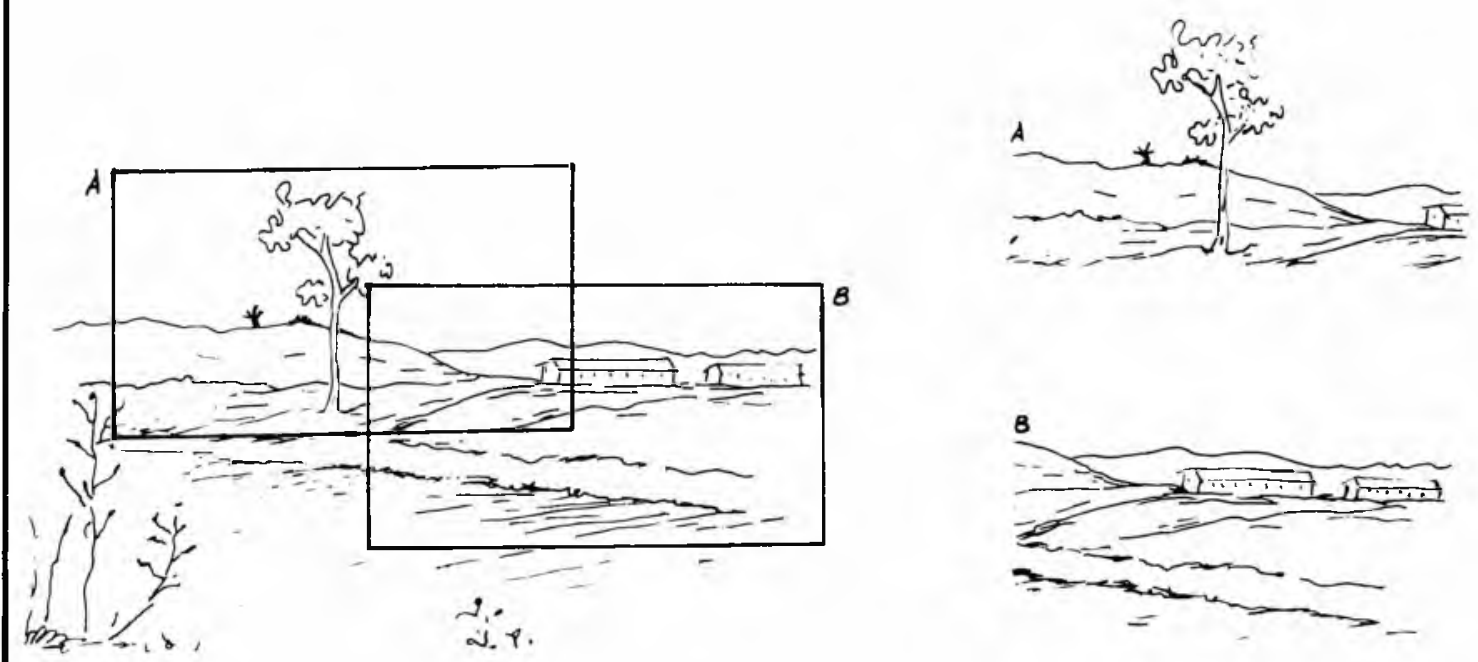

Fig. 1 Paisagem vista por dois observadores diferentes, seria a mesma paisagem? 
Essa postura de delimitação geográfica é importante para os efeitos de comunicação. Para a transferência de conhecimento entre duas pessoas é necessário que, tanto a nível de imagem como a nível descritivo, o transmissor e o receptor tenham mentalizados o mesmo objeto. Para contornar essa dificuldade Monteiro (1978) tenta definir a paisagem através de um objeto central (Figura 2). Essa definição ajudou, mas não eliminou as diferenças de extensão do objeto de estudo.

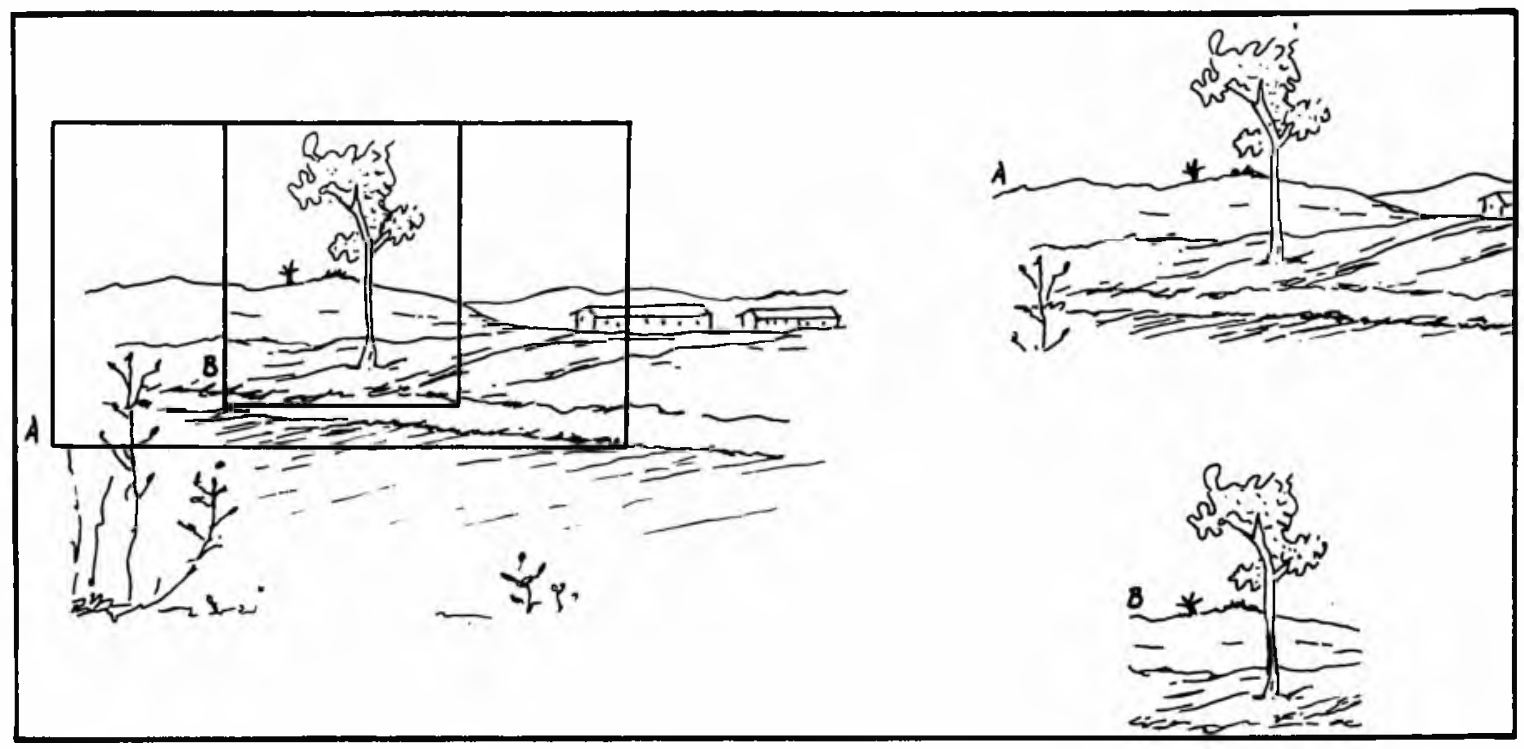

Fig. 2 Paisagem vista por dois observadores diferentes, tendo a árvore como objeto central. Seria a mesma paisagem?

A paisagem é um elemento pontual geograficamente e a determinação dessa pontualidade é uma preocupação fundamental para o arquiteto paisagista (FAUUSP, 1990). Sandeville Jr. (1990) define essa preocupação com a pontualidade na medida em que a paisagem seja o instante captado pela percepção mecânica-tecnológica: a fotografia. Nessa, como nas outras, as preocupações devem ser levadas ao cubo, já que falamos apenas em escala bidimensional quando a paisagem é, na verdade, tridimensional.

O instante captado, além de geográfico é temporal. Se o território se torna paisagem quando tem descritas as suas características fisiográficas (Laurie, 1978), a permanência dessas características se dá numa determinada faixa de tempo, ou seja, numa pontualidade histórica. É fácil verificar que esse tempo é variável de acordo com os componentes da paisagem. Enquanto algumas paisagens conservam suas características por muito tempo, outras têm suas fisionomias variáveis em tempo menor. Essas mudanças, no entanto, são uma necessidade da interação social, exigida pela antropização (Magnoli, 1987), ou pela variação fisiológica natural dos elementos vivos da paisagem (Figura 3). 

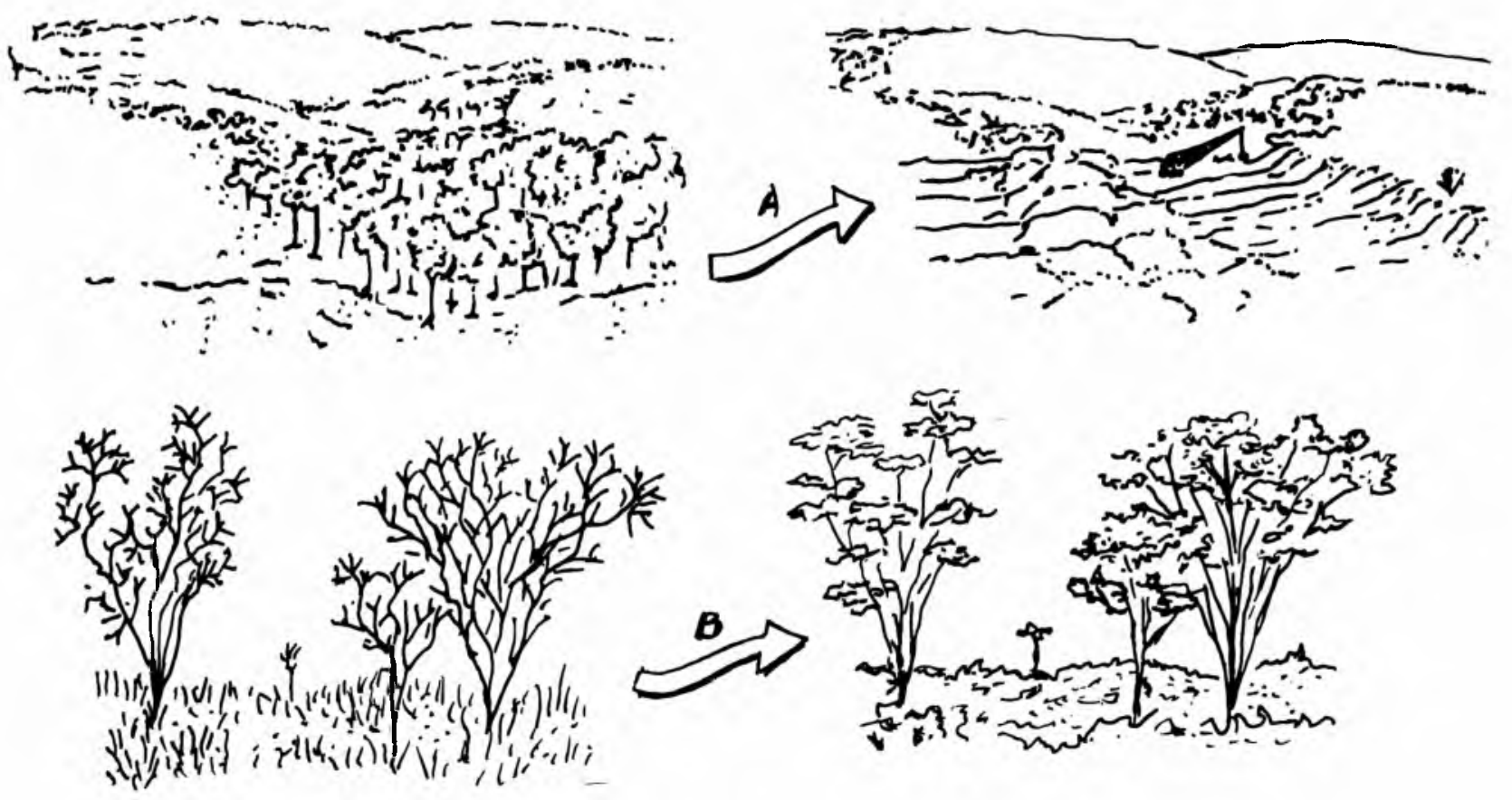

Fig. 3 Transformaçōes da paisagem: a) antrópica em longo prazo. b) fenológica em curto prazo. Seria a mesma paisagem?

Fontes: a) Minter (1990). b) Hueck (1972) Desenho sobre foto.

A transformação brusca da paisagem, como a dos aspectos fenológicos, quanto à estética, pode ser comparada à antropização em um ambiente turístico sazonal como temporadas de praia ou estâncias religiosas, onde a paisagem do fim de semana é completamente diversa da dos dias comuns. Essa pontualidade histórica é inclusive relegada a um segundo plano freqüentemente nos projetos de paisagismo, já que poucas vezes se estuda o impacto de um aglomerado de pessoas num ambiente, ou de um agrupamento de carros de várias cores num estacionamento. Reconhecidamente a influência biológica na paisagem é de difícil manejo devido ao seu caráter fortuito e passageiro (Gonçalves, 1990).

A personalização da leitura da paisagem (Meinig, 1976 e Pellegrino, 1990) pode ser extrapolada para o valor funcional além do estético, onde a função da paisagem deve ser direcionada a grupos com personalidade definida como renda, idade, profissão, etc. Esse usuário, personificado, terá maximizada a utilização através da exploração biótica e do potencial abiótico conforme Bertrand (1972). Essa personificação do usuário é importante principalmente pelas diversas funções e maneiras de leitura da paisagem como especificadas por Pellegrino (1990). Isso leva a um conceito de pontualidade antrópica onde a paisagem deve ter sua função especificada para cada tipo de usuário. 
Além do fator qualidade há que se levar em conta o fator quantidade especificados na literatura (IEF, s/d; Organização Mundial da Saúde, 1965), embora esse fator seja de somenos importância quando comparado àquele, acrescentadas variáveis importantes como localização e distribuição.

\section{A ABORDAGEM GEOMÉTRICA}

A paisagem como o espaço de terreno que se abrange num lance de vista é um conceito simplista demais em termos geográficos para não falar nas interações que ele deixa de abordar. Tricard (1980), apesar de reconhecer essas interações peca em considerar a paisagem com uma extensão determinada.

Sauer, citado em Pellegrino (1986), reconhece a individualidade da paisagem em unidades individuais de área, que Klink (1974) caracteriza como ecossistemas, cartografados por um artifício de representação.

Buscando a origem dessa dificuldade na compreensão do próprio termo "paisagem" a análise comparativa com as denominações geométricas do elemento "reta", talvez possa auxiliar o entendimento e a criação de um termo mais compreensível.

Os geômetras chamam de reta a uma seqüência de pontos de dimensão linear, mas sem começo nem fim. À semelhança disso, a paisagem é, também, uma entidade sem fim nem começo e portanto impossível de ser representada em sua totalidade (Figura 4).

RETA

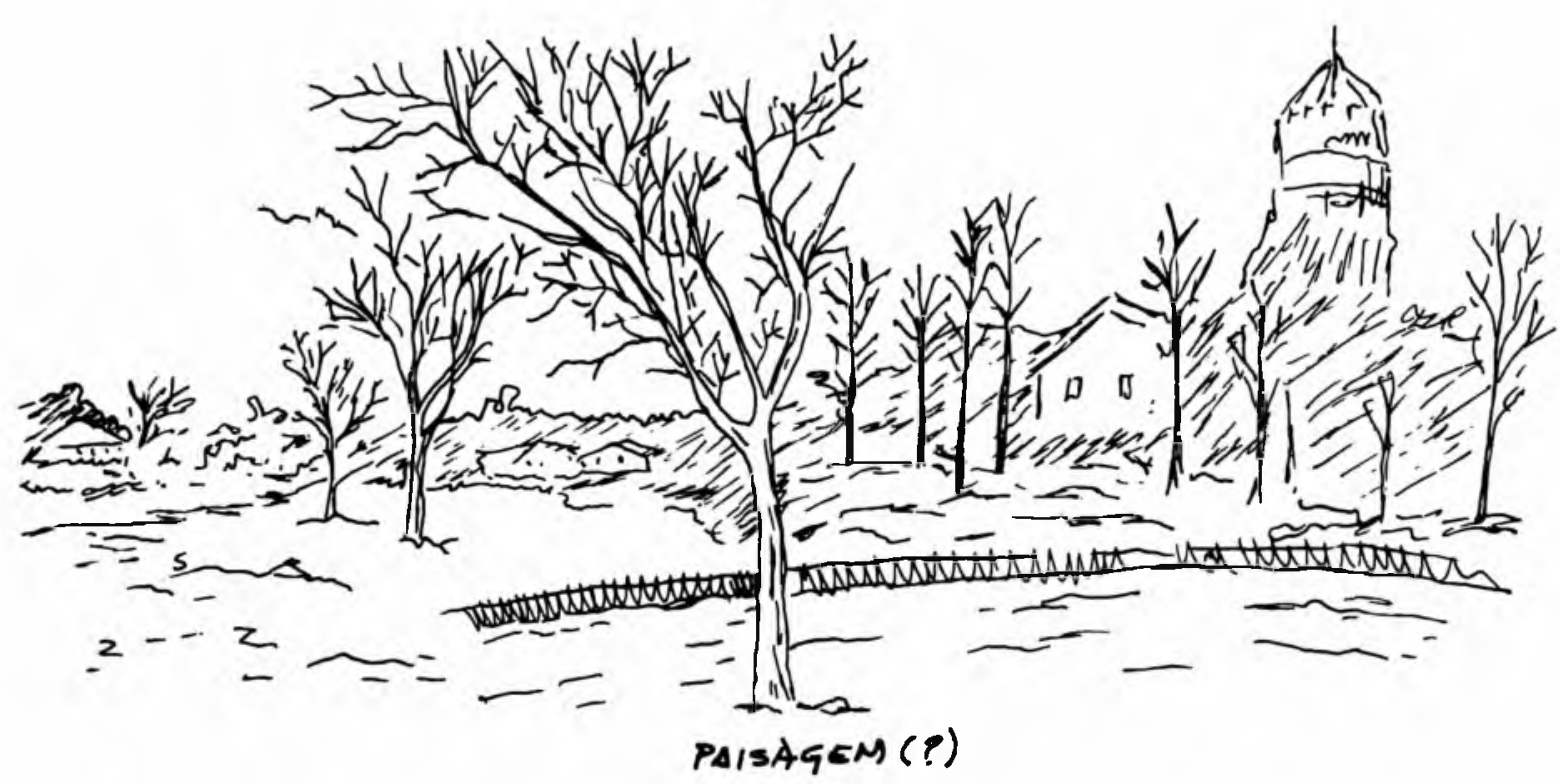

Fig. 4 Reta e paisagem possuem conceitos semelhantes. 
A dificuldade de trabalhar um elemento sem dimensão levou os geômetras à caracterização de uma porção da reta, ou seja, uma definiçâo do objeto de estudo destacada do elemento reta a que se denominou "segmento de reta", aplicável ao elemento paisagem (Figura 5).
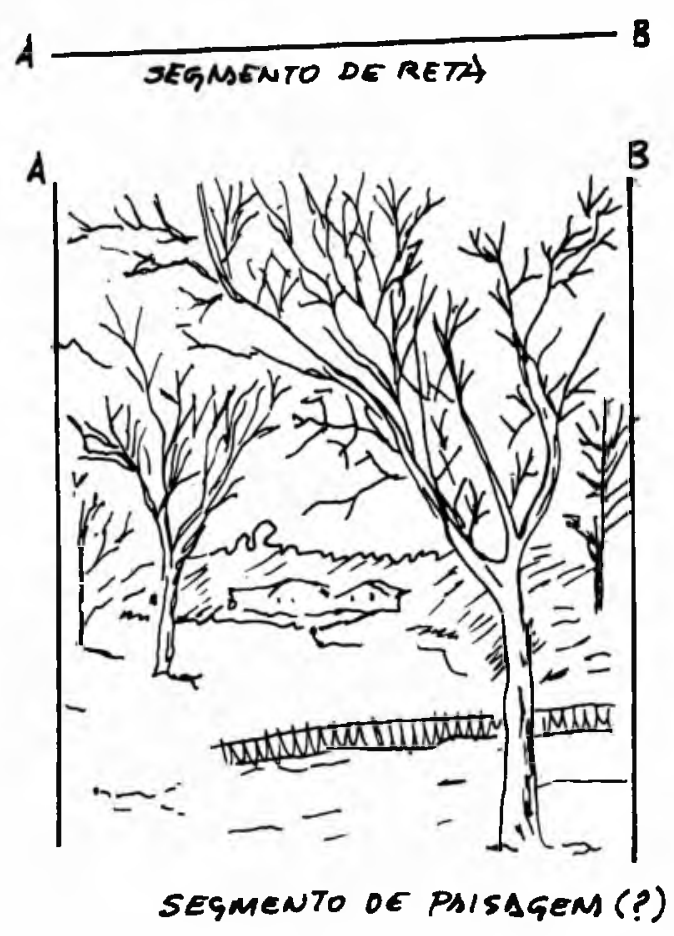

Fig. 5 Definição do objeto em estudo.

O simplismo do elemento geométrico deve ser acrescido, é claro, de todas as variáveis outras a que está sujeita a paisagem como: tridimensionalidade, interações, associações, etc., isto equivale à introdução do conceito de unidade elementar de paisagem (Delpoux, 1974), excluindo qualquer critério de dimensão, mas completado com a idéia de dinâmica funcional. Essa idéia é retomada por Klink (1981) onde a regionalização natural leva em consideração a massa e balanço de energia, com proposição da divisão da paisagem em unidades naturais.

O estudo de semelhança com a geometria não ajuda em nada a divisão física da paisagem, mas a adoção de um termo diferente pode facilitar a comunicação e a compreensão entre os profissionais, na necessidade existente de se referir ao "instante" em que se estuda (trabalha) e que é caracterizado por uma pontualidade geográfica, histórica e antrópica. Assim, a denominação de "segmento de paisagem", "recorte de paisagem", "unidade elementar de paisa- 
gem", "unidade natural", ou qualquer outro termo que o valha, é de somenos importância perto da caracterização do objeto.

\section{O PROFISSIONALISMO}

A origem da arquitetura paisagística, ou simplesmente paisagística, aconteceu quando o homem sentiu necessidade de modificar o ambiente, adaptando a natureza para sua conveniência (Barsa, 1980). Essa modificação tem sido interpretada de modo diferente, desde o radicalismo em prol de um equilíbrio ecológico até a complacência de mudanças radicais em favor do homem. Tanto na quebra do equilibrio por meio de técnicas apropriadas (Pellegrino, 1986) como na permanência dele, precisa-se reconhecer, como adverte McHarg (1969), que a natureza oferece oportunidades e restrições à interveniência do homem.

A arquitetura paisagistica, ao contrário do que muito se pensa à respeito, se ocupa com a utilidade do sítio além do valor estético e essa ocupação já norteava os criadores dos inúmeros jardins renascentistas italianos (Barsa, 1980). Erroneamente pensa-se que o projeto paisagístico se confunde com um projeto arquitetônico e que a arquitetura paisagística é uma profissão que tem o cultivo e distribuição da vegetação como fator principal quando, em verdade, esses fatos são apenas pontos de um contexto mais geral. Ao contrário do arquitetônico, o projeto paisagístico não termina com o traçado no papel, levando mesmo anos até que se consolide definitivamente.

A ASLA, Sociedade Americana de Arquitetos Paisagísticos vem procurando definir a profissão e atribuições do arquiteto paisagista desde 1909, quando definiu arquitetura paisagística como sendo "a arte de adaptar a terra para o uso humano e diversão".

Em 1950, lembrou-se de acrescentar ao suporte físico, a terra, o que estava sobre ela e a arquitetura paisagística ficou definida como "a arte de arrumar a terra e os objetos sobre ela para uso humano e diversão".

Em 1972, além da arte, aplicou a ciência. A adaptação e arrumação são traduzidas em planejamento, desenho e administração, mencionando já, como fator predominante a agricultura. A arquitetura paisagística ficou definida como sendo "a arte de aplicação de princípios científicos para a terra (seu planejamento, desenho e administração) para o público, com uso do conceito de administração agrícola da terra".

Em 1975, a ASLA frisa o uso do natural e do construído, acrescentando à arte e à ciência os valores culturais e a conservaçāo dos recursos com propó- 
sitos de recreação além da beleza, definindo arquitetura paisagística como "a arte do desenho, planejamento ou administração da terra, arranjo natural e artificial de elementos através da aplicação de conhecimentos culturais e científicos com conservação de recursos e administração agrícola, com finalidade que resulte em uso e propósitos de recreação".

Alguns anos depois, sem data definida, a arquitetura paisagística é encarada como profissão e, além dos atributos anteriores, é designada à pesquisa, com criação de técnicas e conhecimentos políticos, conservando os recursos humanos com beleza e segurança e a ASLA a definiu assim: "arquitetura paisagística é a profissão que aplica princípios artísticos e científicos pará a pesquisa, planejamento, desenho e administração de ambiente natural e construído, criação e técnica, conhecimento cultural e político no arranjo planejado de elementos naturais e construídos com conceitos de administração agrícola e conservação dos recursos humanos, natural e construído, resultando em um ambiente com uso estético, seguro e propósitos de recreação".

Em 1983, apesar de rotular de definição, a sociedade se preocupou muito mais com as atribuições profissionais que propriamente com a definição do termo. O texto se apresenta mais como um código de ética e uma relação de atribuições do arquiteto paisagista: "para o propósito de preservação, desenvolvimento e engrandecimento da paisagem inclui (a arquitetura paisagística): investigação, seleção e alocação da terra e recursos hídricos para usos apropriados; estudos de probabilidade; formulação de critérios gráficos e de escrita para planejamento e desenho de programas de construção na terra; preparação, revisão e análise de planos diretores para uso da terra e desenvolvimento; produção de planos diretores, planos de greides, drenagem, irrigação, plantio e detalhes de construção; especificações, custos e relatórios; colaboração no desenho de estradas, pontes e estruturas com respeito e requisitos funcionais; observações de campo e inspeção de área construída, restauração e manutenção"

O que se observa na prática é que a arquitetura paisagística não é uma atribuição específica dos arquitetos que a dividem, principalmente, com os profissionais da área agronômica. Dada a formação de cada um pode-se perceber que os enfoques são diferentes nos projetos, observando-se que os profissionais da área agronômica trabalham melhor o vegetal, ao passo que os arquitetos trabalham melhor o construído. $O$ curriculum escolar para formação de um profissional mais completo deve ser feito com as ciências biológicas, exatas, sociais, além de exigir do aluno eventual tendência para as artes plásticas. 


\section{BIBLIOGRAFIA}

ASLA. Sociedade Americana de Arquitetos Paisagísticos.

BERTRAND, G. Paisagem e Geografia Física Global: Esboço Metodológico. São Paulo, IGEOGUSP, 1972, 27 p. (caderno de ciências da terra, 13).

DELPOUX, M. Ecossistema e Paisagem. Instituto de Geografia da USP, São Paulo, 1974, 23 p. (série métodos em questão, 7)

ENCICLOPÉDIA BARSA. Encyclopaedia Britânica Editores Ltda. vol. II p. 504, 1980.

FAUUSP. Plano de Ensino da Disciplina Paisagismo: Paisagem Urbana e Regional. Grupo de Disciplinas Paisagem e Ambiente. Departamento de Projeto, São Paulo, 1990.

GONÇALVES, W. Paisagem. São Paulo, FAUUSP, 1990. 5 p.

HOLLANDA, A. B. de. Novo Dicionário da Língua Portuguesa, 2. ed., Rio de Janeiro, Nova Fronteira, 1986.

HUECK, K. As Florestas da América do Sul: Ecologia, Composição e Importancia Econômica. Trad. de Hans Reichardt. São Paulo, Polígono. Universidade de Brasilia, 1972.

IEF. Manual de Arborizaçāo. Belo Horizonte, Instituto Estadual de Florestas/CEMIG. s.d., 22 p. il.

KLINK, H. J. Geoecology and Natural Regionalization: Basis for an Environmental Research. Tubingen, 1974 (Applied sciences and development, 4).

. Geoecologia e Regionalização Natural: Bases para a Pesquisa Ambiental. FFLCHUSP, Departamento de Geografia, São Paulo, 1981, 24 p.

LAURIE, M. An Introduction to Landscape Architecture. Londres, Pitman Publishing Limited, 1978. $214 \mathrm{p}$.

MAGNOLI, M. M. Ambiente, Espaço, Paisagem. In: Ensaios II, FAUUSP. Departamento de Projeto, 1987.

McHARG, I. Design with Nature. Garden city, New York, Doubleday, 1969.

MEINIG, D.W. The Beholding Eye: Ten Version of the Same Scene. Louis'Ville, Landscape Architecture, 1976. 65 p.

MINTER - Instituto Brasileiro do Meio Ambiente e dos Recursos Naturais Renováveis. Manual de Recuperaçāo de Áreas Degradadas pela Mineração: Técnicas de Revegetação/IBAMA. Brasîlia: IBAMA. 1990, 96 p.

MONTEIRO, C. A. F. Derivações antropogênicas dos geossistemas territoriais no Brasil e alterações climáticas: perspectivas urbanas e agrárias no problema da 
elaboração de modelo de avaliação. In: SIMPÓSIO SOBRE A COMUNIDADE VEGETAL COMO UNIDADE BIOLÓGICA, TURÍSTICA E ECONÔMICA. São Paulo, 1978. Anais. ACIESP. 1978. 248 p.

PELLEGRINO, P.R.M. Por um Design Ambiental - Espaço de Aplicação: a Região de Sorocaba - In: Paisagem e Ambiente - Ensaios. São Paulo, FAUUSP, 1986. p. 26-46.

A Paisagem Possivel. In: Paisagem e Ambiente Ensaios III. São Paulo, FAUUSP, 1990. p. 69-75.

SANTOS, M. Espaço e Método. São Paulo, Nobel, 1985. 88 p.

SANDEVILLE Jr. E. Arte e Ambiente numa condição contemporânea - O espaço/ação de uma nova sensibilidade. In: Paisagem e Ambiente - Ensaios III. São Paulo, FAUUSP, 1990. p. 85-96.

SOTCHAVA, V. B. O Estudo dos Geosistemas. São Paulo, IGEOGUSP, 1977. 52p. (série métodos em questão, 16).

TRICARD, J. L. F. Paysage et Ecologie. 1980.

WORLD HEALTH ORGANIZATION. Environmental Health Aspects of Metropolitan Planning and Development. Geneva, 1965. (Technical report series, 297). 